F. A. Pronk and J.C. Lodder,

University of Twente, P. O. Box 217.

7500 AE Enschede, The Netherlands.

\section{ABSTRACT}

The co-evaporation technique has been used for deposition of Co-Cr layers. Deposition has been done under intermediate angle of Incidence of opposing vapour streams. The layers showed a single phase hcp poly-crystalline structure. The (002) plane turned out to be tilted towards the direction of the Co source. The layers showed good perpendicular magnetic behaviour although the magnetic anisotropy axis was also inclined towards the Co-source. Because of the opposing angle of incidence for $\mathrm{Co}$ and $\mathrm{Cr}$ atoms, a process-induced segregation takes place which causes a relative high coercivity also at low process temperatures. A simple model for the segregation effect can explain the relation between the existance of a non-magnetic region and an increased coercivity of the Co-Cr film.

\section{INTRODUCTION}

Co- $\mathrm{Cr}$ fllms are most promising as a perpendicular magnetlc recordling medium. $D_{50}$ values of over $250 \mathrm{kBPI}$ have been reported.[1]. Inltially the layers were produced by r.f.sputtering[2] but later on various other methods have been used. In recent years the emphasis has been shlfted towards high-rate techniques $11 \mathrm{ke}$ magnetron sputtering [3] and vacuum evaporation[4]. The latter is the most promising from the point of view of deposition rate. This technology could provide a production process that could be competitive to the present particulate tape product ion [5].

The most intensive work on evaporated $\mathrm{Co}-\mathrm{Cr}$ layers has been done by Sugita et.al. [4,6] who have researched the cont1nuous deposition process. They have also studied angle of Incidence effects and found that for a relatively small angle $\left(\alpha_{1}<30^{\circ} ; \alpha_{i}=\right.$ deviation from normal incidence) no deterioration of the crystal structure could be observed. Others $[7,8]$ have reported on the highly orlentated $\mathrm{Co}-\mathrm{Cr}$ layers, deposited on $\alpha-\mathrm{Ge}$ or $\mathrm{T} 1$ seedlayers which show a good recording performance. These results show that a high quality medlum prepared by evaporation can be obtained.

In most of the published work on evaporation of $\mathrm{Co}-\mathrm{Cr}$ an alloy source is applied. This results in problems with composition control caused by exhaustion of the $\mathrm{Cr}$ in the source[9]. An alternative for this method is the dual source evaporation technology. In this method a geometrical problem arlses which could introduce a composition gradient along the layer thlckness. This can be accepted because a continuous composition gradient can offer some merits[10].

In thls paper results are shown from experlments, using the co-evaporation technique. Especlally the properties that might arise from the not ideal situation of intermediate oblique incidence are discussed.

\section{EXPERIMENTAL SETUP}

The deposition is carrled out using a Leybold Heraeus L560 high vacuum system equiped with 2 e-beam evaporation sources. The individual deposition rate of the sources is controlled by two quartz-crystal thlckness monitors. The geometry of the sources and substrate is shown in flg.1. During deposition, the substrate position is fixed. The angle of incidence to the substrate is $21^{\circ}-31^{\circ}$ (depending on the position on the substrate holder) and the $\mathrm{Co}$ and $\mathrm{Cr}$ atoms arlve from opposite directions. During deposition, the end pressure is at a level of $P_{e}<10^{-6} \mathrm{mbar}$, also at higher process temperatures. The deposition rate was $8 \mathrm{~A} / \mathrm{s}$.

Single crystal Si wafers were used as substrate material. The substrates were tightly mounted against a substrate plate which is heated from the backside by an infra-red heater. The monitored process temperature $\left(T_{p}\right)$ is not the actual substrate temperature $\left(T_{\text {sub }}\right)$ but the control temperature of the infra-red heater. $T_{p}$ is expected to be proportionally smaller than the actual $\mathrm{T}_{\text {sub }}$ and was in the range $50-300^{\circ} \mathrm{C}$.

From every deposition cycle, several samples were analysed, each from a different position on the substrate holder and thus showing a change in their composition and slightly in their thickness.

The magnetlc properties were measured by V.S.M and a torque magnetometer. The structure of the layers was analysed by X-ray diffraction $(\mathrm{Co}-\mathrm{K} \alpha)$ and the so called rocking curve was measured. TEM analysis was performed in order to determine crystallinity and grain size.

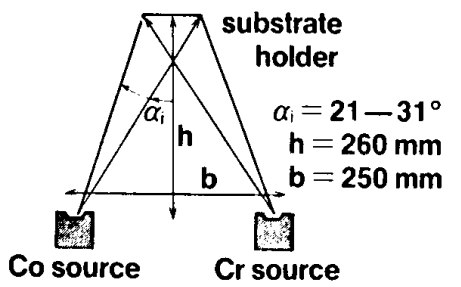

Fig. 1 Basic geometry of the process

\title{
RESULTS AND DISCUSSIUN
}

Structural analysis

Our first concern is if a proper crystallographic structure has been obtained. The TEM bright and dark fleld images and diffraction pattern indicated a polycrystalline texture with an average graln size of $10-15 \mathrm{~nm}$ for layer thickness $\delta=80 \mathrm{~nm}$. The samples with lower $\mathrm{Cr}$ content showed the largest grain size. The samples were also analysed by $X$-ray diffraction and only a $(002)$ diffraction peak at $2 \theta=52.4^{\circ}$ could be observed, indicating that only a hcp structure, perpendicularly orientated towards the substrate is formed in the layer. From this peak the so called rocking curve was measured. The half-value width $\Delta \theta_{50}$ of the rocking curve peak, was $12-14^{\circ}$ for $\delta>200 \mathrm{~nm}$. This is a relatively high value for $\mathrm{Co}-\mathrm{Cr}$ layers; however, because of the oblique incldence this could be expected. Improved geometry and application of seedlayers will improve this orlentation.

The rocking curve was measured for several rotation axes of the samples. The longitudinal (LP)and transversal (TP) measurement plane are defined in Fig.2.

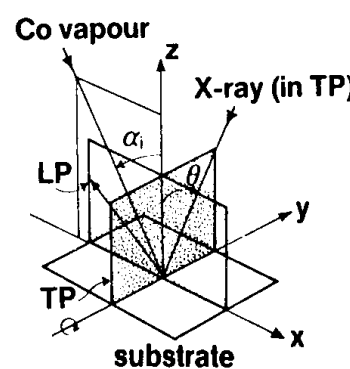

Fig. 2a

Definition of the measurement planes

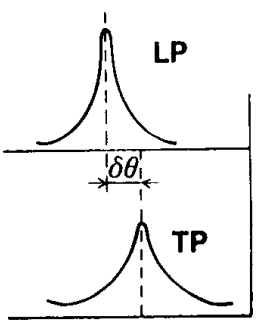

Fig. $2 b$

Shift of peak in rocking curve 
It was found that in the LP, the peak of the rocking curve was shlfted over an angle $\delta \theta$ from the peak that occured in the TP. Also a lower peak value was measured in the TP. This shift in the longitudinal plane is caused by a preferential inclination of the [001] crystal axis towards the Co-source. The shift angle at $\delta=400 \mathrm{~nm}$ is $\delta \theta=9-11^{\circ}$, Independent of the angle of incldence but seems to depend on the layer thlckness $\left(\delta \theta \sim 5-7^{\circ}\right.$ for $\left.\delta<200 \mathrm{~nm}\right)$.

Because of the oblique incidence, we might expect a canting $\beta$ of the columns from the perpendicular direction according to[11]:

$$
\beta=\arctan \left(0.5 \tan \alpha_{1}\right)
$$

In our case the canting w1ll be towards the direction of the Co source because most of the material in the layer is Co. Generally $\beta$ is larger than the observed shlft in the rocking curve. Unfortunately we have not yet performed an observation of the cross-sectiona view by SEM in order to observe the actual angle of canting of the columns. However, on the basis of other experiments, we can obtain Information on this canting. This will be discussed in combination with the results of our torque measurements.

Concerning the materlal properties of the layers, we can summarize a polycrystalline single-phase hcp structure with an orientation which is preferentially inclined through a number of degrees towards the direction of the incidence of the Co atoms.

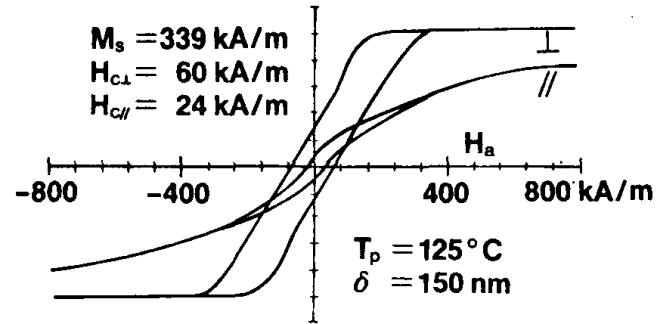

Fig. 3 Typical M-H loop of the Co-Cr layers

Magnitic properties

In Fig. 3, a typical $M-H$ loop of the deposited layers is shown. A good perpendicular magnetlc behaviour is obtained. The inplane coercivity ( $\mathrm{Hc}$, ) of the layers is 25-35 kA/m. F1g.4 shows the perpendicular coercivity ( $\mathrm{HCl}_{1}$ versus saturation magnetization $\left(M_{8}\right)$. The thickness of these samples is near 200nm and deposition was carried out at several values of $T_{p}$. At constant $M$, a higher $\mathrm{Hcl}$ is observed for 1ncreasing $T_{p}$, as is usually found for $\mathrm{Co}-\mathrm{Cr}$ layers. A comparison is shown of $\mathrm{HC \perp}$ values of Ouchi[12] for $1 \mu \mathrm{m}$ sputter-deposited layers at $\mathrm{T}_{\text {sub }}=200^{\circ} \mathrm{C}$ and those estimated from data of Suglta [4] for $0.15 \mu \mathrm{m}$ evaporated at $T_{\text {sub }}=160^{\circ} \mathrm{C}$. It can be seen that a clear difference between the two methods exists in the high $M_{\text {region. In the former a maximum }}$ is found near $M=700 \mathrm{kA} / \mathrm{m}$ whlle in the latter thls maximum occurs at lower $M$ values. Th1s will be due to the difference in energy of the vaporized atoms which is much higher in sputtering. Increasing $T_{p}$ might partlally compensate for the lower energy level at evaporation. However, for our co-evaporated samples, al ready at low $T_{p}=50^{\circ} \mathrm{C}$, an increased $\mathrm{Hcl}$ is observed. A correlation between this result and the existance of a "Cr-rich" part in the Co-Cr layer can be found if we observe the relation between $M$ and the mean $\mathrm{Cr}$ concentration $\left(C_{m}\right.$ ) as was measured by XRF. (see fig.5). At higher $\mathrm{Cr}$ contents, a deviation from the bulk $M_{B}$ value is measured. This deviation is more pronounced at higher $T_{p}$. Already at $T_{p}=50^{\circ} \mathrm{C}$ a considerable volume of " $\mathrm{Cr}-\mathrm{rlch}$ " $\mathrm{Co}-\mathrm{Cr}$ must exist. This cannot only be due to a segregation by ad-atom diffusion during film growth. Therefore a process-induced segregation must also exist. This will be caused by shadowing effects

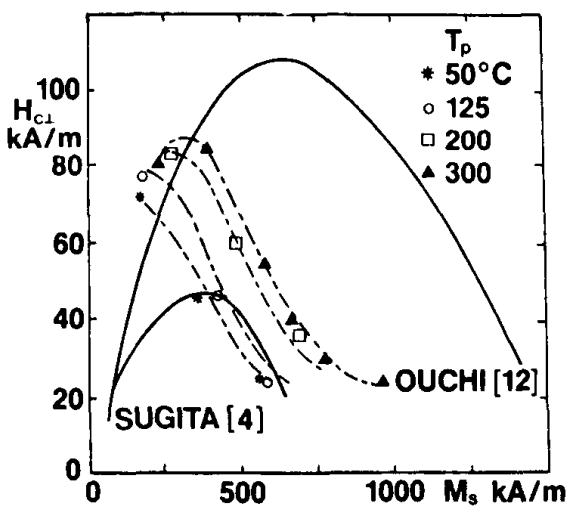

Fig. 4 Relation between $H_{c 1}$ and $M_{s}$ of Co-Cr layers.

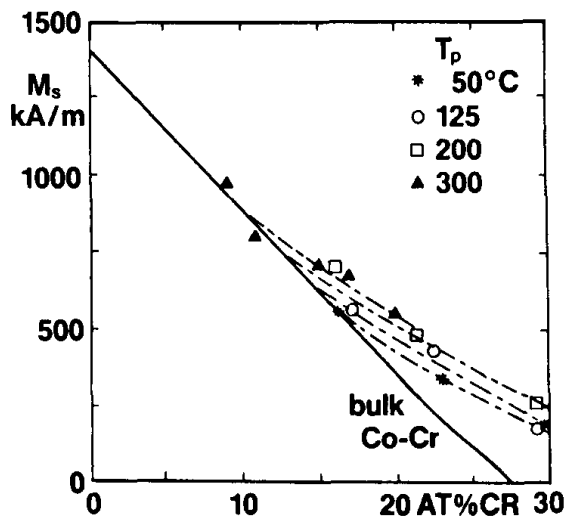

Fig. 5 Relation between $M_{s}$ and the mean concentration.

during deposition under the opposing intermediate oblique incidence. A good treatment of such type of problem can be found in [13] showing these effects to occur in $\mathrm{Fe}-\mathrm{Cu}$ layers deposited at varying angles of incidence.

The relation between the existance of this segregated state and the occurance of an increased coercivity of the $\mathrm{Co}-\mathrm{Cr}$ layers could be explained by a model introduced by Andra and Danan[14]. This model is based on a grain boundary with Increased $\mathrm{Cr}$ content which forms pinnig points for domain-wall motion at low peak concentration and a non-magnetic boundary resulting in particulate behavlour at peak concentrations higher than 25-27 at\% $\mathrm{Cr}$

We tried to fit the model, using (2) for the $\mathrm{Cr}$ distribution in a column, to our measured relation between $C_{m}$ and $M_{k}$.

with:

$$
C(d)=C_{c}+\left(C_{p}-C_{c}\right) * e^{-(D-d)^{2} / 2 w^{2}} \quad(0<d<D)
$$

$C_{c}=$ column centre $\mathrm{Cr}$ concentration, $C_{p}=C r$ concentration at column boundary. $D=c o l u m n$ dlameter $W=$ measure for the column boundary width.

We modifled the model to a better fit to the results of Sugita[6]. We assume $C_{p}$ to depend only on $C_{c}$ and $a$ constant. $S_{g}$, denoting the degree of segregation. Further we assume W/D to be constant for a certain $C_{c}$, independend of the degree of segregation. This can be understood from the fact that at higher $T_{p}$ generally both segregation (and thus $W$ ) but also the column size $D$ increase. We assume $W$ to be proportional to the potential amount of $\mathrm{Cr}$ that can segregate; $\mathrm{C}_{c} * \mathrm{D}$. Thus:

$$
C_{p}=S_{g} \bullet C_{c} \quad(3) \text { and } W / D=W_{o} / D \bullet C_{c}
$$




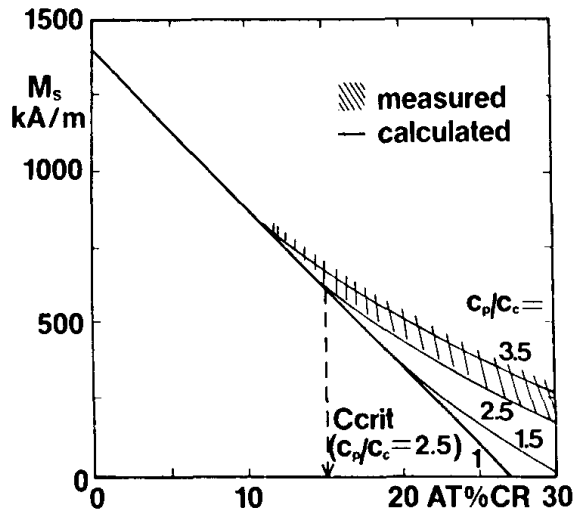

Fig. 6 Comparison between measured and calculated relation between $\mathrm{M}_{\mathrm{s}}$ and $\mathrm{C}_{\mathrm{m}}$.

The fitting parameter $W_{0} / D=0.005$ will give a good fit with Sugita's results. We only have to change the relative peak concentration in this simple model in order to fit it to our $M_{B}\left(C_{m}\right)$ curve. A reasonable agreement is obtained at $C_{p}=2.5 \sim 3.5 \cdot C_{c}$ as is shown in Fig. 6. It is clear in this figure that a significant deviation from the line of homogeneous distribution of $\mathrm{Cr}$ starts at a value $\mathrm{C}_{\mathrm{m}}=\mathrm{C}_{\text {crit }}$ whlch depends on the point when the peak concentration exceeds 27 at $\% \mathrm{Cr}$ and thus a non-magnetic boundary is introduced. In most of the cases $\mathrm{C}_{\text {crit }}$ is near 15 at\% $\mathrm{Cr}$. However, also at $\mathrm{C}_{\mathrm{m}}<\mathrm{C}_{\mathrm{cr} / \mathrm{t}}$ the segregation might exist but will not lead to an easlly observable devlation from the line for bulk saturation magnet isation.

In other words, $C_{c r i t}$ will indicate the start of the formation of the non-magnetic boundary and thus also the change in the reversal mechanism from domain-wall pinning into particulate behaviour. In our case $\mathrm{C}_{\mathrm{cr} \text { t }}=12-17 \mathrm{at} \%$ which $1 \mathrm{~s}$ also near the point where an Increased HcL is observed(fig.4) as could be expected from a more particulate behaviour.

Magnet ic anisotropy

In magnetic layers, deposited under oblique incidence a magnetic anisotropy axis is found which is rotated towards the tilted columns[15]. Although our layers showed a typlcal magnetic behavlour of a layer with a perpendicularly orientated magnetic anisotropy, an inclined magnetic anisotropy exists. This could be detected by the torque magnetometer and using the method of Swaving e.a.[16] to calculate the anisotropy constant and the direction of the anisotropy axis For samples with $\delta>200 \mathrm{~nm}$ we found a $\mathrm{K}_{1}>15^{*} 10^{4} \mathrm{~J} / \mathrm{m}^{3}$. (With $\mathrm{K}_{1}=\mathrm{K}_{\mathrm{u}}-1 / 2 \mu_{\mathrm{o}} \mathrm{M}_{\mathrm{g}}{ }^{2}$ ) The angle of the anlsotropy axis towards the film normal $\left(\gamma_{a}\right)$ depends on the angle of incidence $\alpha_{1}$ on the sample. In table $I$ the results are given together with the values of the other important directlons which have been found. These samples were deposited at $T_{p}=125^{\circ} \mathrm{C}$ and $\delta=400 \mathrm{~nm}$.

Table I Relation between angle of incidence and other relevant angles for several material properties.

\begin{tabular}{|c|c|c|c|c|}
\hline $\begin{array}{c}\text { substrate } \\
\text { position }\end{array}$ & $\alpha_{1}$ & $\beta$ & $\delta \theta$ & $\gamma_{a}$ \\
\hline I & $21^{\circ}$ & $11^{\circ}$ & $9-11^{\circ}$ & $9^{\circ}$ \\
II & $26^{\circ}$ & $14^{\circ}$ & $9-11^{\circ}$ & $14.5^{\circ}$ \\
I I I & $3^{\circ}$ & $17^{\circ}$ & $9-11^{\circ}$ & $16^{\circ}$ \\
\hline
\end{tabular}

It can be seen that the anisotropy direction more or less colncides with the expected column canting. This would imply a significant contribution of shape anisotropy to the magnetic anisotropy. However, the appearance of the shift in the rocking curve also indicates a small rotation of the crystal axis towards the column direction and thus the magnetic crystal anisotropy will also be rotated although this will not completely explain the full rotation of the magnetic anisotropy axis. We planned to further investigate this.

\section{CONCLUSION}

The deposition by co-evaporation under intermediate oblique incidence and opposing vapour streams has some significant influences on the properties of $\mathrm{Co}-\mathrm{Cr}$ layers. In our investigations we found, besides the usually found properties, some process induced effects: - a preferential inclined orlentation of the single phase hcp structure towards the canted column.

- a rotation of the magnetic anisotopy axis to the canted column.

Both effects might be related to each other but the rotation of the crystal axis will not fully explain the rotation of the magnetic anisotropy axis. This might indicate that a shape anlsotropy term will also occur. Notwithstanding this inclined anlsotropy, the layers showed good perpendicular behaviour with high anisotropy energy. Based on the magnetic measurements we found:

- that at relative low process temperature we could obtain a high $\mathrm{Hc} \perp$ (upto $70 \mathrm{kA} / \mathrm{m}$ ) in the $\mathrm{M}_{\mathrm{B}}$ range 200-500 $\mathrm{kA} / \mathrm{m}$.

Th1s is due to a process-induced segregation caused by shadowing during deposition.

- By fitting a simple model for the Cr distribution to the measured $M_{s}\left(C_{m}\right)$ curve, a $C_{c r i t}$ can be defined at which point a non-magnetic boundary between magnetic $\mathrm{Co}-\mathrm{Cr}$ parts is formed. This $\mathrm{C}_{\text {crlt }}$ correlates with the increase of Hcl vs $M_{s}$ thus indicating the relation between the occurance of this non-magnetlc boundary and a particulate like behaviour of the magnetic reversal mechanlsm.

In general, these layers deposited under intermediate oblique incidence showed good perpendicular magnetic properties which might be improved by optimized geometrical deslgn.

\section{ACKNOWLEDGEMENT}

This work was sponsored by the European Community and by Leybold Heraeus GmbH, Hanau, FRG.

\section{LITERATURE}

( 1]S. Yamamoto, Y. Nakamura, S. I wasak1, Session AB-01, Intermag Conference Tokyo, 1987.

[ 2]S. I wasaki, K. Ouch1, IEEE Trans. Magn. Vol. Mag. 14-5, 1978, p849.

[ 3]H. Kobayash1, JEE (Japan) Vol. 19, no. 187, July 1982, p64.

[ 4]R. Sugita, F. Kobayashi, IEEE Trans. Magn. Vol. Mag. 18-6, 1982, p1818.

[ 5]K. Nakamura, Tutorial Session Intermag Conference Tokyo, 1987.

[ 6]R.Sugita, IEEE Trans. Magn. Vol. Mag. 20, 1984, p687.

[ 7] M. Futamoto, Y. Honda, H. Kaki bayashi, K. Yoshida, IEEE. Trans. Magn. Vol. Mag. 21-5, 1985, p1426.

[ 8] K. Nakamura, N. Echigo, R. Sugita, N. Kaminaka, IEEE Trans. Magn. Vol. Mag. 22-5, 1986, p1182

[ 9]S. Honda, J.Storer

IEEE Trans. Magn. Vol. Mag. 22-5, 1986, p337.

[10]M. Yasumura, K. Ouchl, S. I wasak1, Session DG-03, Intermag Conference, Tokyo 1987.

[11]A. Feuersteln, M. Mayr, IEEE Trans. Magn. Vol. Mag. 20-1, 1984, p51.

[12]K. Ouchi, Ph. D. thesis, Tohoku University Sendai, 1984.

[13] S. Ke i toku, T. Kam1 mor1, M. Goto, Jap. Journ. Appl. Phys. Vol. 25-11, 1986, p1668.

[14]W. Andrä, H. Danan, IEEE Trans. Magn. Vol. Mag. 23-1, 1987, p62.

[15] K. Hara, T. Hash 1 moto, E. Tat sumoto, Journ. Phys. Soc. Japan 28, 1970, p254.

[16]S. Swaving, G. J. Gerritsma, J. C. Lodder, Th. J. A. Popma, Journ. Magn. and Magn. Mat. 67, 1987, p155 